\title{
MONSEÑOR JUAN LARREA HOLGUÍN: ÍCONO DEL DERECHO ECUATORIANO
}

BISHOP JUAN LARREA HOLGUIN: ICON OF ECUADORIAN LAW

\section{Pablo Zambrano Albuja*}

Resumen: Se recoge en estas líneas una reseña bibliográfica sobre el jurista ecuatoriano más prolífico, Monseñor Juan Larrea Holguín, expuesta con ocasión de la séptima edición del Premio Internacional Juan Larrea Holguín. En concreto, se recoge su faceta humanista, su servicio de Dios y al derecho $\mathrm{y}$, especialmente, su contribución con la academia jurídica nacional e internacional.

Palabras clave: Derecho ecuatoriano, juristas ecuatorianos, civilistas ecuatorianos, Historia del derecho, Derecho internacional

Abstract: These lines collect a bibliographic review of the most prolific Ecuadorian jurist, Monsignor Juan Larrea Holguin, exposed on the occasion of the seventh edition of the Juan Larrea Holguin International Award. Specifically, it includes his humanistic facet, his service to God and law, and especially his contribution to the national and international law academy.

Keywords: Ecuadorian Law, Ecuadorian Jurists, Ecuadorian Civilists, History of Law, International Law

Sumario. I. Introducción. II. Un humanista. III. Una vida al servicio de Dios y del derecho. IV. Su contribución con la academia. V. Su pasión por el derecho. VI. Conclusiones.

* Presidente Ejecutivo at Cámara de Industrias y Producción del Ecuador. Profesor de la Universidad de Los Hemisferios (Quito, Ecuador). pablozambrano@hotmail.com 


\section{INTRODUCCIÓN ${ }^{1}$}

En mi calidad de Presidente de la Cámara de Industrias y Producción y de la Federación Nacional de Industrias del Ecuador, quiero agradecer a la Universidad de los Hemisferios por esta invitación, así como al Director y profesores del máster en derecho, por conferirme el gran honor de dar unas palabras que nos permita conocer un poco más de la vida de Monseñor Juan Ignacio Larrea Holguín, ilustre jurista ecuatoriano, a quien tuve el privilegio de conocer y tratar en varias ocasiones, por cuanto fue un entrañable amigo de mi padre y, coincidencias de la vida de mi suegro también, quienes compartieron con Monseñor Larrea su interés por la ciencia jurídica, la ética y el humanismo, al haber sido los tres abogados formados en la Pontificia Universidad Católica del Ecuador, casa de estudios en la cual yo también estudié.

El concurso de investigación jurídica y política, que hoy nos convoca, es un justo homenaje de esta ilustre Universidad de los Hemisferios, así como de la querida Corporación de Estudios y Publicaciones, quienes han tenido a bien organizar este premio, con el nombre de quien se puede calificar como el más representativo jurista de la historia ecuatoriana, Mons. Juan Ignacio Larrea Holguín, un verdadero referente del foro ecuatoriano, inspirador de centenas de estudiantes y practicantes del derecho a nivel nacional e internacional, a través de su compromiso con la investigación jurídica, fomentando con su actividad profesional los valores más nobles del ser humano.

\section{UN HUMANISTA}

A Monseñor Juan Larrea Holguín se le pueden destacar sus múltiples facetas: jurista, profesor, asesor legal, investigador, consejero, formador de juventudes, sacerdote y hombre de Dios. Por lo tanto, se lo puede definir como un humanista. Destaca mucho su amor a Dios, a los pobres, a la historia, las letras, la teología, al deporte, a la pintura, pero en especial a la ciencia del derecho.

Es el autor ecuatoriano más prolífico en el ámbito jurídico, al tener a su haber más de 200 libros en materia de Jurisprudencia, así como otros 100 libros publicados en áreas como historia, ética, religión y cívica. Fue un

\footnotetext{
${ }^{1}$ Comunicación enviada con motivo del acto de premiación del VII Premio Internacional Juan Larrea Holguín, llevado a cabo en la Universidad de Los Hemisferios (Quito, Ecuador).
} 
hombre profundamente estudioso y conocedor del derecho, la realidad nacional y la ética. Un hecho importantísimo a destacar, es que fue el primer jurista ecuatoriano que comentó en extenso todo el Código Civil de Don Andrés Bello, obra que varios de sus antecesores - como Luis Felipe Borja Pérez - intentaron y no acabaron.

En el ámbito público, prestó su servicio y su talento a la sociedad ecuatoriana, al ser coautor de las reformas a la Constitución y promotor de la más importante reforma al Código Civil Ecuatoriano en 1970 y la vital tarea de codificación de varias leyes como el Código del Trabajo, Ley de Compañías, Ley del Banco Nacional de Fomento, la del Instituto de Colonización Amazónica, entre otros trabajos que detallaremos más adelante.

\section{UNA VIDA AL SERVICIO DE DIOS Y DEL DERECHO}

Nació en Buenos Aires en 1927, cuando su padre cumplía las funciones de Diplomático. Su hogar, cristiano y fiel a los valores morales más preclaros, lo conformaron su padre, su madre y sus hermanos. Precisamente su padre, el Dr. Carlos Manuel Larrea Rivadeneyra, fue un destacado diplomático e historiador, que prestó sus servicios al Ecuador en momentos muy complejos de la historia nacional.

La pasión por el derecho de Monseñor Larrea Holguín, se forjó por motivo de la agitada historia del Ecuador en los primeros 50 años del siglo $\mathrm{XX}$, donde aparecieron las nuevas leyes como el divorcio, la reforma agraria y donde tanto había sufrido la religión, todo lo cual había dejado mella en su alma, y esa herida hizo que se decantara por la carrera de Derecho.

Realizó sus estudios en emblemáticas universidades: la Pontificia Universidad Católica del Ecuador, en la que inició sus estudios de la mano de brillantes juristas: Aurelio Espinoza Pólit y Julio Tobar Donoso; la Universidad Estatal de Roma (La Sapienza), la Universidad Pontificia de Santo Tomás de Aquino (el Angelicium), posteriormente continuaría sus estudios religiosos y en filosofía en Italia y España. Se especializó en áreas como el Derecho Civil, Derecho Canónico, Derecho Romano y Religión.

En 1949 solicitó ingresar al Opus Dei porque decidió seguir el llamado a la santidad sin dejar de lado sus quehaceres profesionales. Le llamó la atención la forma de vida del Opus Dei luego de vivir en la residencia, muy frugal y sencilla del fundador de esta institución de la Iglesia, San Josemaría Escrivá de Balaguer, a quien conoció y fue su amigo, siendo en 1952 el primer ecuatoriano miembro de esta prelatura personal. El mensaje del santo era que todos estábamos llamados a vivir una gran santidad en medio del 
mundo, cada uno en su profesión. El joven Larrea se sintió muy atraído por este mensaje y ejerció como abogado y profesor universitario durante muchos años.

Más tarde fue ordenado sacerdote. Pese a ello, nunca dejó de lado el Derecho. Continúo con las publicaciones de estudios y también con la docencia.

\section{IV.SU CONTRIBUCIÓN CON LA ACADEMIA}

Monseñor Larrea Holguín, fue el primer exalumno de la Pontificia Universidad Universidad Católica del Ecuador, que dio una cátedra en su propia universidad luego de optar y ganar un concurso de merecimientos y oposición. Su tesis doctoral fue el primer grado doctoral rendido en la PUCE, e incluso, a manera de anécdota, fue docente de algunos de sus antiguos compañeros.

Durante los años 60 y 70 impartía sus clases al más puro estilo de la vieja escuela: empezaba puntualísimamente las clases persignándose $\mathrm{y}$ rezando un Padrenuestro o un Avemaría, y diciendo dos palabras "Sedes Sapientiae", animando a los alumnos a contestar "ora pro nobis".

Sus explicaciones eran muy claras y buenas, muy imbuidas de la doctrina de la Iglesia, pero iba con mucho ritmo. Por ejemplo, durante el primer año se veían los cuatro primeros tomos de su comentario al Código Civil, avanzando treinta o cuarenta páginas por día. Aunque era serio, los alumnos le admiraban y supo ganarse su amistad.

Fue docente por alrededor de 30 años, en ciudades del país como Quito, Guayaquil e Ibarra. Impartió cátedras incluso más allá del Derecho, como de Comercio Internacional y Religión.

En 1992 inauguró el Instituto Pedagógico Católico para la formación de maestros, construido con donaciones y sin fines de lucro.

Un hecho muy importante a destacar, es que para 1965 Monseñor Larrea, que ya tenía una buena trayectoria como escritor de obras de Derecho, con el objeto de prestar ayuda a sus alumnos y al foro ecuatoriano, junto con René Bustamante Muñoz y Ramón Eduardo Burneo, funda la Corporación de Estudios y Publicaciones (CEP), la cual es la mayor editorial jurídica del país hasta la actualidad, publicando los textos oficiales de las leyes y códigos, así como obras jurídicas de autores ecuatorianos y extranjeros.

La labor que ha cumplido la Corporación de Estudios y Publicaciones (CEP), ha sido invaluable, no solo por el servicio que presta sino por la pulcritud y exactitud de los textos que publica, lo cual demuestra la seriedad 
con la cual esta institución trabaja, valga esta oportunidad para felicitar a sus directivos, que han continuado la obra del ilustre maestro Larrea Holguín.

\section{V.SU PASIÓN POR EL DERECHO}

Durante más de 10 años (1952 y 1962) actuó en los juzgados y tribunales del Ecuador y en ciertos procesos fuera del país.

Su criterio jurídico era considerado como uno de los más objetivos del país. Fue consultado en numerosas oportunidades por partidos de derecha, centro e izquierda, con la finalidad de conocer su opinión para la posterior aprobación de varias políticas públicas e iniciativas legales.

Antes de dedicarse de lleno al sacerdocio, fue secretario de la Comisión Nacional de la UNESCO durante los años 1953 a 1954; en 1955 fue nombrado Procurador de la Caja Nacional del Seguro Social; al año siguiente fue Procurador Fiscal de la República; Procurador Electoral de 1957 a 1961 y Vicepresidente de dicho Tribunal de 1960 a 1961. También fue asesor de múltiples entidades: de la Presidencia de la República, de la Corte Suprema de Justicia, del Ministerio de Relaciones Exteriores, del Ministerio de Agricultura y de la Comisión Legislativa Permanente del Congreso Nacional.

En varias ocasiones fue llamado a tribunales nacionales e internacionales, por jueces y árbitros, para rendir su versión como perito en derecho dada su experticia en derecho nacional e internacional, ante lo cual incluso escribió textos pedagógicos.

Promovió además numerosas normas y reformas inspiradas por los principios cristianos, a favor de los derechos de las personas, de la mujer, de la familia, de la educación y de la libertad religiosa.

Su criterio jurídico era considerado como uno de los más objetivos del país. Fue consultado en numerosas oportunidades por partidos de derecha, centro e izquierda, con la finalidad de conocer su opinión para la posterior aprobación de varias políticas públicas e iniciativas legales.

Desde la ordenación sacerdotal, Monseñor Larrea Holguín no solo se separó de cualquier actividad política, sino que ni tan siquiera alguien le pudo escuchar una opinión partidista; sin embargo, por sus relaciones familiares conservó siempre amistad con varios ex presidentes de la República, a los que procuró hacer el bien en sus necesidades materiales y espirituales

Mons. Javier Echavarría mencionó sobre Mons. Juan Larrea que no intervino en cuestiones políticas a pesar de haber militado activamente en un partido, cuando era más joven. Sin embargo, sabía dar doctrina para que 
quienes se ocupan de la cosa pública actuasen con responsabilidad, en servicio a los ciudadanos, católicos o no.

Como mencioné en líneas anteriores, este ilustre jurista, ícono del derecho ecuatoriano, participó activamente en la Ley de Reforma Agraria y en la Ley de Administración del Estado. Además, colaboró de forma activa en la codificación del Código Civil, Código del Trabajo, Ley de Compañías, Instituto de Colonización Amazónica, incluso asesoró a movimientos provida previo a la Asamblea Constituyente de 2007.

Quiero destacar su labor en las reformas al Código Civil, primero en 1970, con la llamada Ley 256, que buscaba la igualdad entre hombre y mujer, la igualdad de toda clase de hijos, así como la regulación de varias cuestiones contenidas en los diversos libros del Código Civil (personas, bienes, sucesiones, obligaciones y contratos).

Mons. Larrea sobre la ley comentó «debo consignar con satisfacción que la Comisión acogió con entusiasmo algunas reformas propuestas, como las tendientes a facilitar el reconocimiento de los hijos, a equiparar los derechos del marido y la mujer, a reprimir la usura, ampliar el patrimonio familiar, extender el dominio público a las riquezas submarinas, entre otras».

La denominada Ley 43 de 1989, también sobre el Código Civil, actualiza algunos aspectos de la reforma de 1970 y se la pone en concordancia con la Constitución de 1979. Introdujo la unión de hecho. Monseñor Larrea destacó los aspectos positivos y observó los negativos de la ley que, en parte, tuvo origen en sus trabajos. Sin embargo, lamentó que en el Congreso se haya dado paso a temas como la unión de hecho ya que esto significaba un "agravio" a la familia tradicional.

En el gobierno del Presidente Sixto Durán Ballén, a quien le dio no solo su amistad sincera, sino que le proveyó de consejo legal y espiritual, Mons. Larrea Holguín fue nombrado miembro de la Junta de Notables que elaboró el proyecto de reforma a la Constitución Política del Estado, proyecto aprobado en gran medida por el Congreso Nacional de la época.

Participó en la creación de la Ley de Libertad Educativa de las Familias en el Ecuador (Ley 69) fue publicada en el Suplemento del Registro Oficial 540, de 4 de octubre de 1994. El objeto de esta legislación, era permitir que las familias ecuatorianas puedan acceder a la educación religiosa de su preferencia. Fue derogada por la Disposición Derogatoria $4^{\mathrm{a}}$ de la Ley Orgánica de Educación Intercultural.

Algunos tergiversaron lo dicho por Mons. Larrea y le acusaron de querer imponer la religión católica; pro él perseguía la posibilidad de recibir clases de religión — de cualquier religión — a las familias que lo solicitaren. La ley establecía que 
«a opción de los padres de familia, se integrarán dos horas semanales de instrucción religiosa y moral en todos los centros educativos oficiales o privados de nivel pre-primario, primario y secundario, sean estatales, municipales o dependientes de otras instituciones públicas o privadas. Mediante la oportuna consulta a los padres de familia del centro respectivo se identificarán las organizaciones religiosas que respondan a sus preferencias» (art. 1).

Mons. Larrea Holguín preparó a más de cuatrocientos profesores de religión católica para afrontar la demanda que en seguida produjo la aplicación de la ley, logrando así compartir su conocimiento y talento con el magisterio ecuatoriano.

He mencionado también, que su obra más célebre "Derecho Civil del Ecuador" consta de 15 tomos, en los cuales comentó en su totalidad el Código Civil de Andrés Bello (vigente en países como Chile; Colombia y Ecuador).

La obra ha tenido cuatro ediciones, una edición de 6 volúmenes; un compendio de 8 tomos titulado Manual de Derecho civil del Ecuador con dos ediciones y otro compendio de 4 tomos más simplificado con tres ediciones; así como una actualización realizada post mortem por otros autores.

Lo escribió de 1965 a 2005. Es la obra con más influencia y más citada en la doctrina y jurisprudencia ecuatoriana. Sus escritos sirven para reconstruir históricamente la voluntad del legislador.

Según datos de webs como Google scholars, centenares de artículos publicados en internet citan la obra de Mons. Larrea Holguín. ${ }^{2}$ Sus libros también abarrotan varias de las bibliotecas de las principales universidades del país.

Después del derecho civil, el segundo gran tema en el que más destacó fue en derecho constitucional. Realizó ublicaciones con comentarios de varias cartas magnas ecuatorianas, como las de 1967, 1979 y la de 1998. De aquí parte esta obra.

Se imprimió en dos volúmenes. Sostuvo que las bases fundamentales del Estado no han cambiado de forma sustancial desde la separación de la Gran Colombia (1830). Destacaba que la Constitución afianzaba Derechos Humanos y garantías de la libertad e igualdad entre todos los habitantes.

El célebre "Manual de derecho internacional privado ecuatoriano" que apareció en 1962, es una obra de las más importantes obras sobre derecho

\footnotetext{
${ }^{2}$ Véase https://scholar.google.com.ec/citations?hl=en\&user=ikhrhUkAAAAJ Se observa que este servicio no analiza todas las citas que se han hecho al autor en medios impresos, ni en la jurisprudencia.
} 
internacional, en especial con las relaciones con el Estado Ciudad del Vaticano. Tuvo mucha influencia de la carrera diplomática de su padre.

Redactó siete capítulos en diferentes libros y decenas de artículos en revistas científicas sobre estos temas, así como varios libros. Esta obra es basada en sus tesis doctorales. Mostraba su postura frente a la separación del Ecuador con la Santa Sede luego de la revolución liberal y destacaba el trabajo de su padre por restablecerlas.

Finalmente, dentro de esta síntesis que estoy haciendo, no quiero de dejar de nombrar a su icónica obra "Historia del derecho ecuatoriano", que la concibe como fruto de su pasión por la historia y por el estudio de la época republicana del Ecuador y por la historia del derecho. Es una obra escrita en conjunto con José Reig Satorres, uno de los principales historiadores del país.

\section{CONCLUSIONES}

Su enfoque humanista le permitió abordar una diversidad de temas a través de una óptica más humana y apoyada en principios éticos y morales (cristianos), que incluso enriquecieron su conocimiento y su experticia jurídica.

Es el jurista más representativo e insigne de la historia ecuatoriana, no solo por su inmenso aporte como catedrático, sino por su influencia en la actualidad sobre temas en legislación y doctrina nacional, y en la concepción del derecho civil.

Al final de su vida, cuando padecía una grave enfermedad, todavía le quedaron arrestos para meterse en una nueva empresa: escribir una Enciclopedia Jurídica de Derecho ecuatoriano (de diez tomos, de los cuales él escribió tres). Eso demuestra su carácter, su compromiso, su valentía y su inmensa capacidad intelectual.

Este premio es un justo homenaje a Mons. Larrea Holguín no solo por abordar dos de las principales pasiones y doctrinas a las que dedicó mucho tiempo de su vida, como lo son la política y el derecho, sino porque incentiva la investigación y el estudio de ellas en favor de una sociedad más justa y solidaria, comprometida con los derechos humanos y los valores éticos, tal como hubiese deseado Mons. Larrea Holguín. 